\title{
A tribute to Stanley John Dudrick
}

\section{Tributo a Stanley John Dudrick!}

Maria Isabel Toulson Davisson Correia, TCBC-MG'10

A storyteller to be compared to other outstanding physicians who were extremely important to the development of Surgery, such as Joseph Lister and Ignaz Semmelweis, or William T. G. Morton and Alexander Fleming - this is my definition for Dr. Stanley J. Dudrick, the "father" of parenteral nutrition. Beyond his pioneer work on parenteral nutrition, to me, Dr. Dudrick was an interesting, open-minded, bubbly man who adored to tell stories.

I could not be more in agreement with his son Stanley Dudrick Jr, who in his Eulogy, at the funeral of his father, on January $25^{\text {th }}, 2020$, said "Reverent or irreverent-there is a good chance of me being struck by lightning! Genuine, unique; sincere, intense and determined; passionate, compassionate; committed and righteous; always caring and loving as a son, brother, husband; father, grandfather; student, teacher, and mentor; colleague, leader, and boss/chief. He never faded from the Yeoman work willing to carry any burden, take on any challenge, dominate any adversity, work diligently and tirelessly for that in which, and for those in whom he believed with meticulous attention and scrutiny"1.

Since the minute I decided to write this tribute, I have, in vain, tried hard to remember where I first met Dr. Dudrick and Theresa (that's how his sweet, quiet wife told me to call her, instead of Mrs. Dudrick). Unfortunately, my memory betrays me, although I think it was way back in the late nineties of the last century, in Venezuela, maybe! (Figure 1).

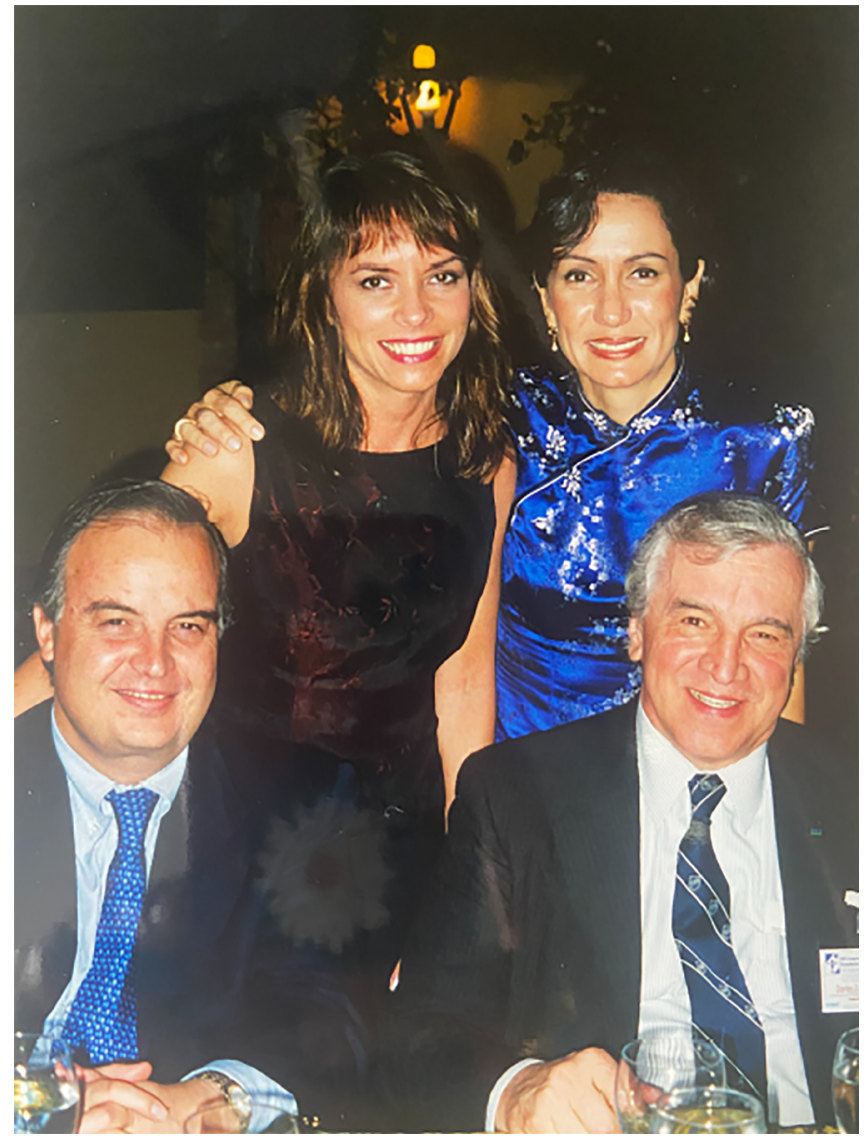

Figure 1. Drs. Stanley Dudrick (USA) and Jaime Escallon (Colombia), Eva Politzer, RD (USA) and the author, Caracas, Venezuela, 1999.

However, this does not matter, as there were many other times we had the opportunity to be in the same events and share ideas.

Aside from our common areas of clinical practice and science (surgery and nutrition therapy), we both cherished dogs, in particular, beagles, the sweetest animals who were his in vivo model to test parenteral nutrition (Figure 2).

1 - Universidade Federal de Minas Gerais, Cirurgia - Belo Horizonte - MG - Brasil. 
The interesting aspect about his choice of beagles, according to him, was because they do not lie and stretch on their backs, which made it possible to implant the central line and fix it on the transition of their neck and torso. When I listened to this story, on a train from Warsaw to Krakow (Figure 3), I had to immediately stand up from my seat, and upfront tell him "sorry Dr. Dudrick, but I fully disagree with you! You have not had the chance to meet Nick".
He looked at me in a state of awe, as if I had said something very unreal, only to be cracking up, when I showed him Nick, my beagle, that commonly lies on his back, paws upward, almost like a sleeping human being. Nonetheless, I have to admit that the courage to disagree with this man was only because this was one more of the many times we had had the chance to talk, and I knew he loved to tell stories, but also to listen to others challenge him.

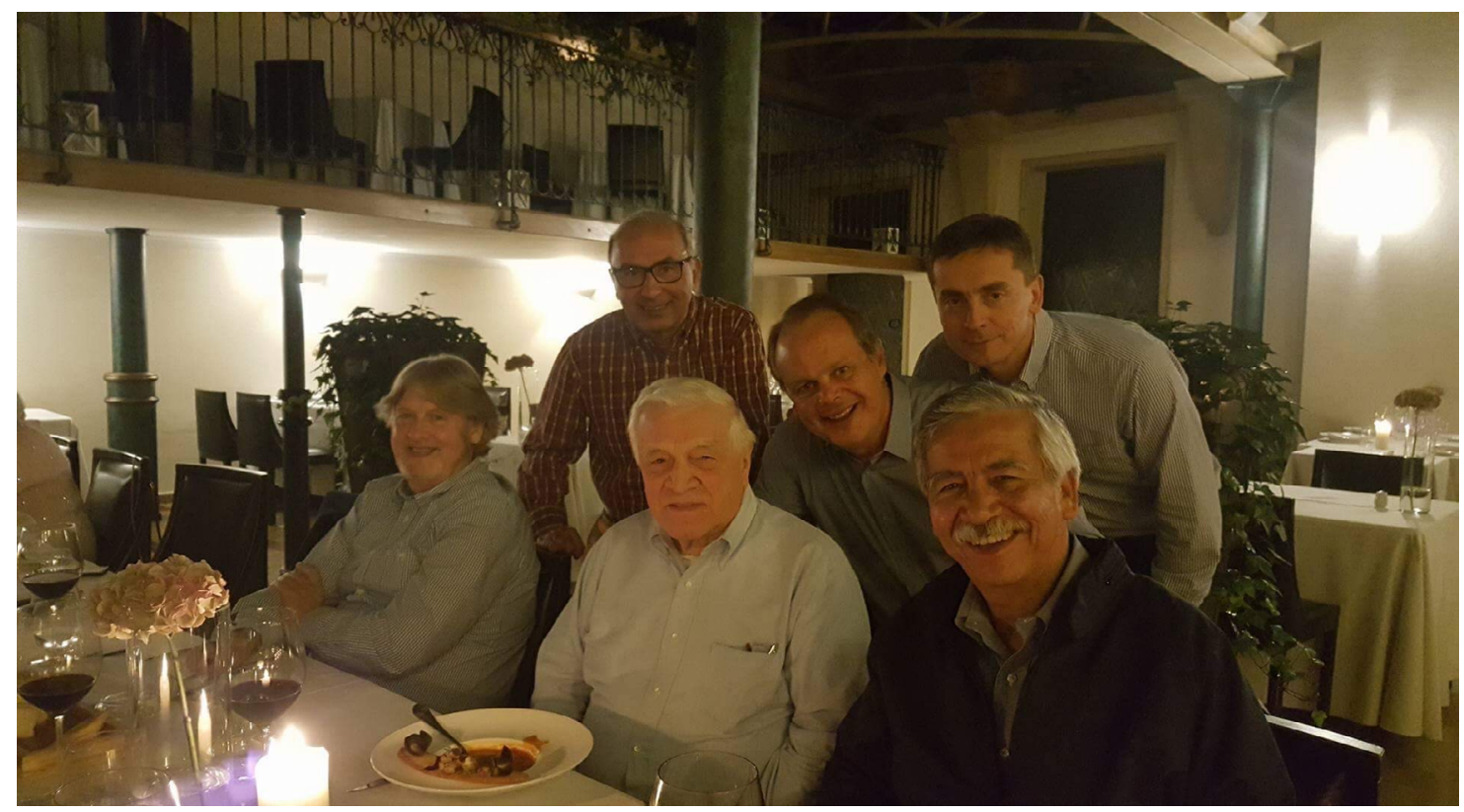

Figure 2. Drs. Stanley Dudrick (USA), on his right side - Gil Hardy, Pharm (UK), on his left side - Dr. Humberto Arenas (Mexico), standing behind him, from the left to the right, Drs. José Eduardo Aguilar Nascimento and Dr. António Carlos Campos (Brazil), and Dr. Stanislaw Klek (Poland), Krakow, Polland, 2017.

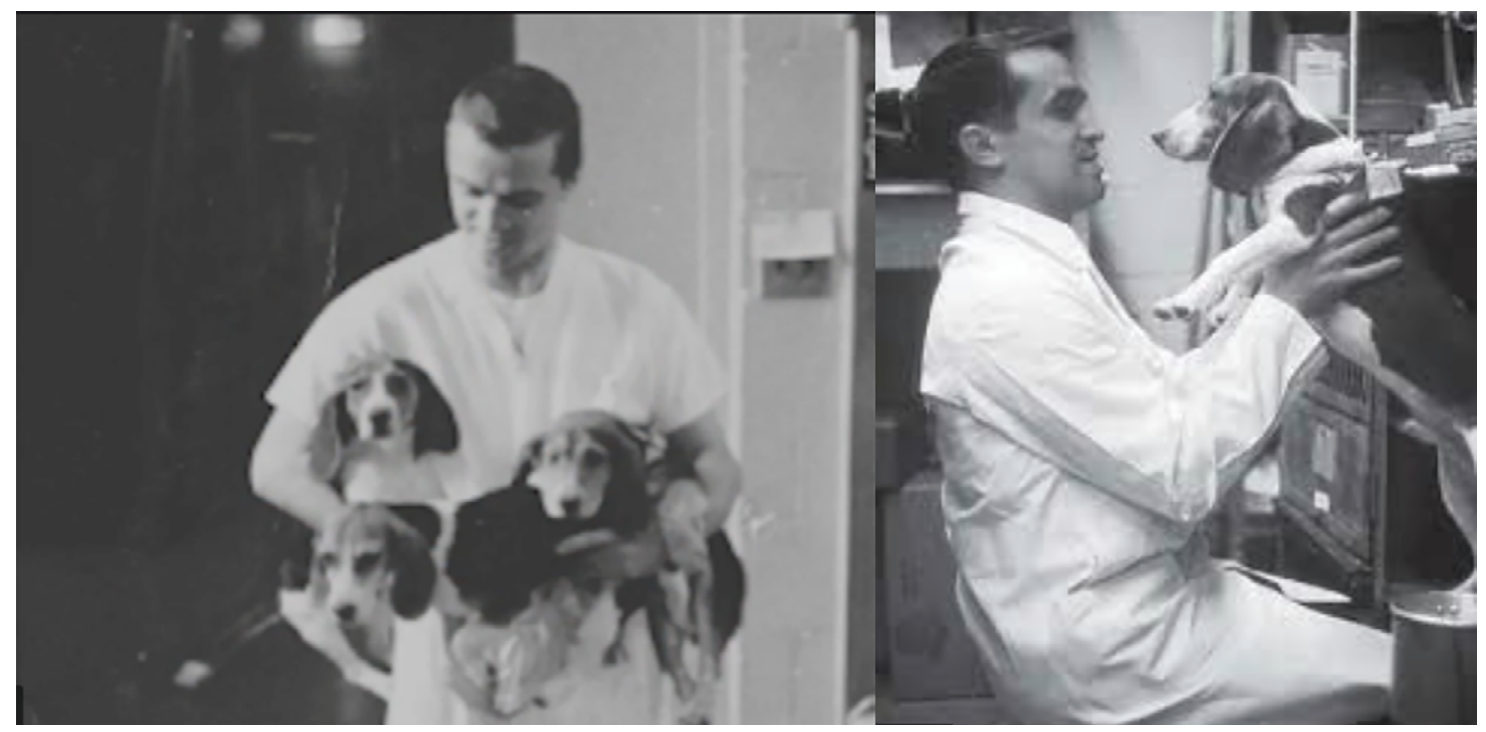

Figure 3. Dr. Dudrick and one of his beagles. 
My memories of Dr. Dudrick go beyond the many scientific events where I had the chance to listen to him share with us on how parenteral nutrition was developed, all the endeavors and drawbacks he had to face to make it viable, and the impact it had on patients' lives. These facets are well depicted in the more than two hundred papers he authored, but those regarding the "common" (if he could be named that) storyteller man are seldom available in the scientific literature, and Dr.

Dudrick was much more than a scientist/physician.

He was someone who could be sitting at a social event, enjoying and cherishing the company of people from everywhere, talking to all who would go by to pay him compliments and allowing them to take pictures with him. And then, on the silence of the bus back to the hotel say "young lady, you dance like a ballerina with that friend of yours", and make the whole bus crack up into laugher, because he would say "you think I do not pay attention at young women dancing" (Figure 4). His humanist and humble behavior always made me sure that a person is what he/she shares with others independently of how important he/she is. And, if there was someone crucial to the survival of many people, HE WAS THE MAN!

Parenteral nutrition, as I have started this tribute, can be ranked at the same level of infection control and anesthesia development, as well as other relevant treatments for surgical patients. As Dr. Dudrick once shared in an interview with the New York Times "It's senseless to pay $\$ 200$ to $\$ 300$ a day for intensive care and then not pay the extra $\$ 50$ to $\$ 100$ for nutrition, it's like buying a Mercedes without any wheels on it" 2,3.

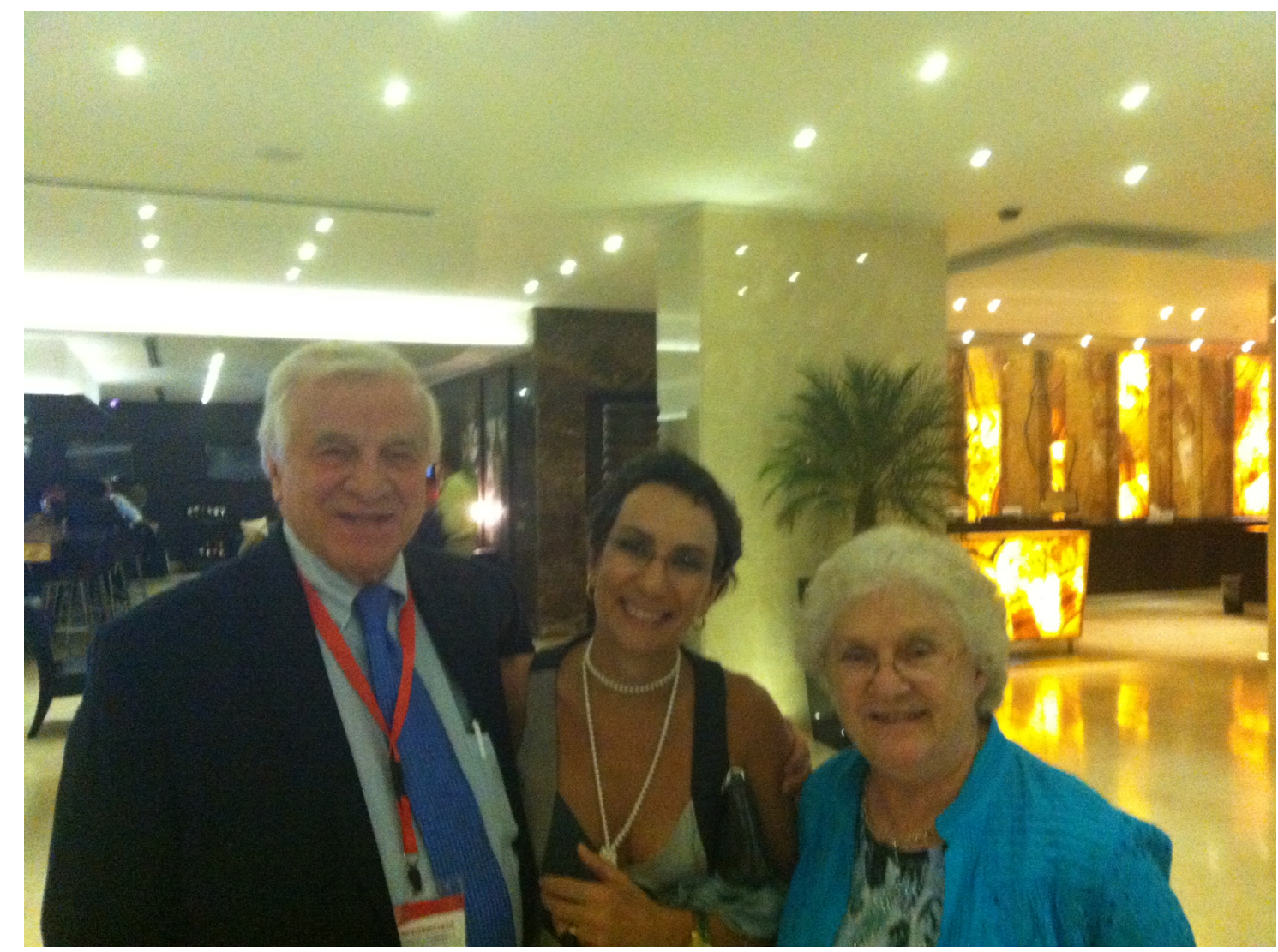

Figure 4. Dr. Stanley Dudrick (USA), his wife Theresa Dudrick and me, Panama city, Panama, 2012. 
Dr. Dudrick published his first research, in 1968, on how parenteral nutrition was able to nourish an infant with atresia of the small bowel from the ligament of Treitz to within $3 \mathrm{~cm}$ of the ileocecal valve, and partial colon atresia. This child was born with $2,3 \mathrm{~kg}$, dropped to $1,816 \mathrm{~g}$ despite the common practice supportive care and, then while being infused with a nitrogen, caloric and other essential nutrient infusion, in the superior vena cava, for 44 days, increased his not only his weight by $1,447 \mathrm{~g}$ but also other anthropometric measurements ${ }^{4}$.

He was the founder and the first president of the American Society for Parenteral and Enteral Nutrition (ASPEN), he chaired the surgery department at four institutions, authored several textbooks and more than two hundred journal articles. But more than that, he was an example to the countless physicians and health care practitioners whom he taught and mentored throughout his life (Figure 5).

Dr. Dudrick left us on January $18^{\text {th }}, 2020$. He leaves his wife Theresa Dudrick, their daughters, Susan Burkholder, Carolyn Henry, Holly Dudrick and Anne Dudrick; their sons, Paul, a surgeon, and Stanley; 16 grandchildren; five great-grandchildren; and a brother, Daniel, as well as many of his scientific admirers, such as myself, and millions of people whom he helped save with parenteral nutrition.

Dr. Dudrick, you have not departed this world, you have risen to another level where you will certainly be telling long and exciting stories. See you sometime in the future!

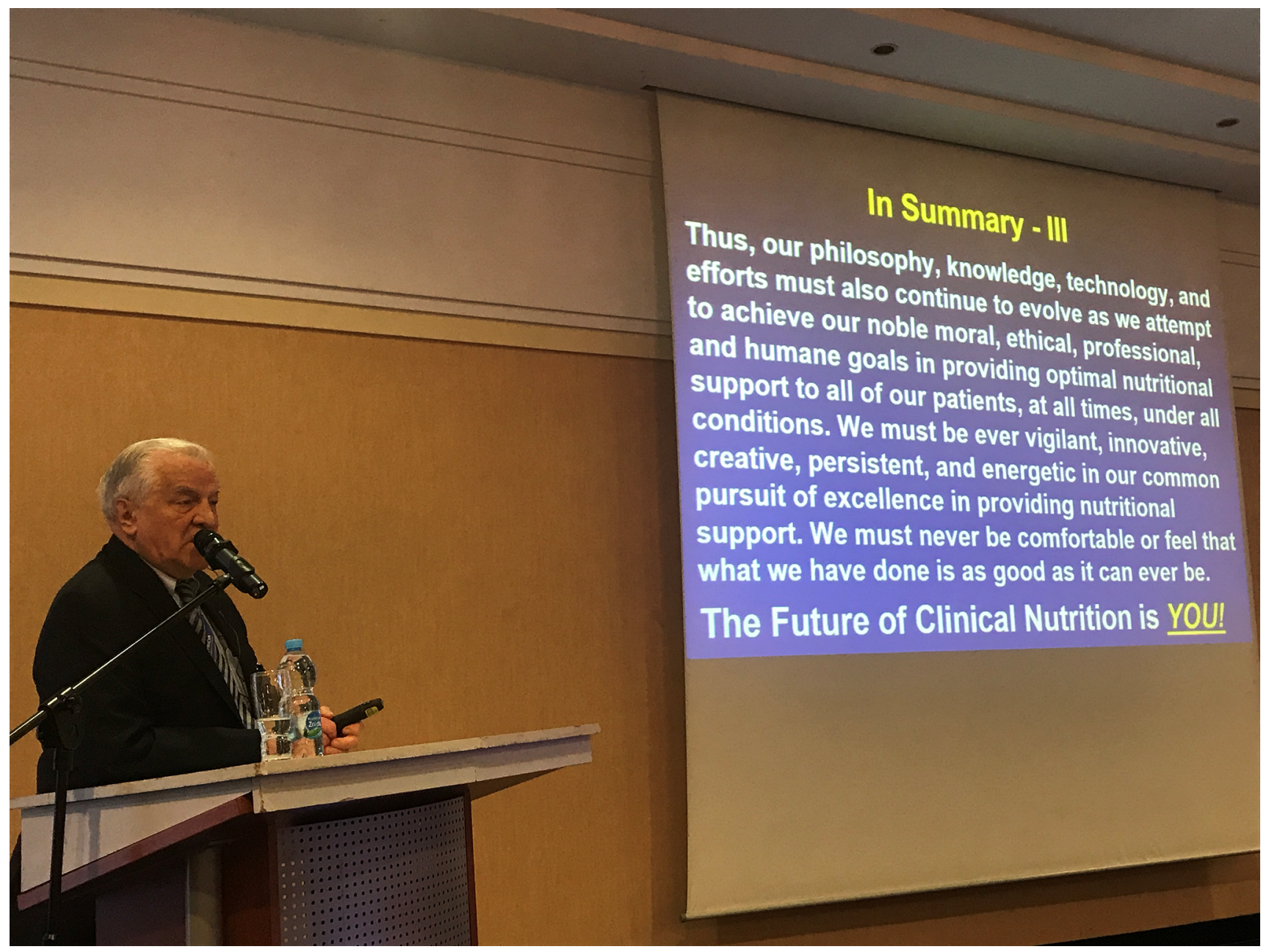

Figure 5. Dr. Stanley Dudrick (USA), while presenting a lecture in Warsaw, Polland, 2017. 


\section{REFERENCES}

1. Tappenden KA, Dudrick SJ, Jr., Chan LN, Daly JM, Steiger E, Barrocas A, et al. Tributes to Our First President and Founding Father, Stanley J. Dudrick, MD, FACS, FASPEN. JPEN J Parenter Enteral Nutr. 2020;44(2):159-71.

2. Hospital Deaths Being Cut by Use Of Intravenous Feeding Technique [press release]. New York Times. 1977.
3. Roberts S. Dr. Stanley Dudrick, Who Saved PostSurgical Patients, Dies at 84. New York Times. 2020.

4. Wilmore DW, Dudrick SJ. Growth and Development of an Infant Receiving All Nutrients Exclusively by Vein. JAMA. 1968;203(10):860-4.

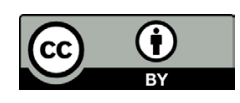

